\title{
Changes in microRNA expression in the MG-63 osteosarcoma cell line compared with osteoblasts
}

\author{
HAO HU ${ }^{1,2}$, YI ZHANG ${ }^{2}$, XIAN-HUA CAI ${ }^{1}$, JI-FENG HUANG $^{1}$ and LIN CAI $^{2}$ \\ ${ }^{1}$ Department of Orthopedics, Wuhan General Hospital of Guangzhou Command; \\ ${ }^{2}$ Department of Orthopedics, Zhongnan Hospital, Wuhan University, Wuhan, Hubei, P.R. China
}

Received May 28, 2012; Accepted August 6, 2012

DOI: $10.3892 / \mathrm{ol} .2012 .866$

\begin{abstract}
Osteosarcoma (OS) is the most common primary malignant bone tumor, particularly in adolescents and young adults. Early diagnosis remains a significant problem in the clinical treatment of OS as we remain far from a comprehensive understanding of the molecular genetic mechanisms and the biology involved. In addition, microRNAs (miRNAs or miRs), a large family of small non-coding RNAs, may provide a greater understanding of OS as they play a complex role in gene expression regulation in vitro and in vivo. In the current study, the differential expression profiles of miRNAs between OS and osteoblast cell lines were investigated by miRNA microarrays and real-time quantitative PCR (RT-qPCR). A total of 268 miRNAs were identified that were significantly dysregulated in OS compared with the osteoblast cell line, including miR-9, miR-99, miR-195, miR-148a and miR-181a, which had been validated as overexpressed, and miR-143, miR-145, miR-335 and miR-539, which were confirmed to be downregulated. This differential expression may aid future OS diagnosis and prognosis prediction and illustration of the potential mechanisms in the oncogenesis, development and metastasis of OS. Bioinformatic research on these differentially expressed miRNAs suggests that they are able to regulate the biological behaviors of OS in a complex and effective manner. Further study on the function of these miRNAs is likely to provide new insights into OS biology and treatment.
\end{abstract}

\section{Introduction}

Although it accounts for less than $0.5 \%$ of all types of cancer, osteosarcoma (OS) is the most frequent primary malignancy of the bone and occurs mainly in adolescents and young

Correspondence to: Dr Lin Cai, Department of Orthopedics, Zhongnan Hospital, Wuhan University, No. 169 Donghu Road, Wuhan, Hubei 430071, P.R. China

E-mail: guke3116@yahoo.com.cn

Key words: osteosarcoma, osteoblast, microRNA, aberrant expression, target gene, function adults (1). The initiation of combinational chemotherapy with aggressive surgical resection has markedly improved the prognosis of OS patients during the last few decades (2). However, the current neoadjuvant chemotherapy outcome for OS remains unsatisfactory in the presence of metastases (3-5). Despite the various efforts of basic research and clinical practice, the molecular genetic mechanisms and the biology involved in OS remain poorly understood. A greater understanding of OS is essential for developing novel approaches to increase survival rates (3).

As a large family of naturally occurring small non-coding RNAs, microRNAs (miRNAs or miRs) employ a post-transcriptional gene regulation mechanism that is involved in numerous cellular processes, playing a role in development regulation, differentiation, cell proliferation, differentiation, apoptosis, cell cycle and tumorigenesis (6). Previous studies have shown that miRNAs may play complex regulatory roles by binding to the 3 ' untranslated region of mRNAs; a single miRNA affects the expression of hundreds of protein-coding target genes, while a protein-coding target gene is regulated by a variety of miRNAs (7).

There is growing evidence that the aberrant expression of specific miRNAs is correlated with various human tumors, including breast cancer, hepatocellular carcinoma, leukemia and colon cancer $(8,9)$. It has been reported that miRNAs regulate cancer cell apoptosis, cell cycle arrest, migration and invasion. The alteration of specific miRNAs may lead to various responses to the chemotherapy and several miRNAs have been demonstrated to participate in the development of tumor metastasis (10).

The current study was designed to investigate the differential expression profiles of miRs between an OS and osteoblast cell line. miRNA expression levels were determined using bead-based array performing oligonucleotide capture probes specific for miRNAs, which is feasible and attractive for its high speed and heightened accuracy. In this study, the differential miRNAs were explored through screening 1,146 mature miRNAs between the MG-63 and hFOB1.19 (HOB) cell lines and the expression of selected miRNAs was confirmed using real-time quantitative PCR (RT- qPCR) in these two cell lines. The tumor function-associated targeted mRNAs of selected miRNAs by bioinformatics and previous literature were also investigated. These findings provide insights into the role of miRNAs in OS. 


\section{Materials and methods}

Cell lines and reagents. Human OS MG-63 and osteoblast HOB cell lines were obtained from the Type Culture Collection of Chinese Academy of Sciences (Shanghai, China). MG-63 cells were cultured in MEM/EBSS (Hyclone, Logan, UT, USA) supplemented with $10 \%$ heat-inactivated fetal bovine serum (FBS, Hyclone), $50 \mathrm{U} / \mathrm{ml}$ penicillin and $50 \mathrm{mg} / \mathrm{ml} \mathrm{strep-}$ tomycin in a humidified incubator with $5 \% \mathrm{CO}_{2}$ at $37^{\circ} \mathrm{C}$. The HOB cells were maintained in the same conditions, except that DMEM/F12 (v/v: 1:1, Hyclone) supplemented with 10\% FBS and $0.3 \mathrm{mg} / \mathrm{ml} \mathrm{G} 418$ (Sigma, St. Louis, MO, USA) was used.

RNA extraction. Total RNA was extracted from each cell line using an miRNeasy Mini kit (Qiagen, Hilden, Germany) according to the manufacturer's instructions. This effectively recovered mRNA and miRNA. RNA concentration and quality were measured using the spectrophotometer (ND-2000, NanoDrop, Wilmington, DE, USA).

miRNA expression profiling by Illumina miRNA microassay. The Illumina ${ }^{\circledR}$ TotalPrep ${ }^{\mathrm{TM}}$ RNA amplification kit (Ambion, Austin, TX, USA) was used in cDNA synthesis and purification with 200 ng total RNA from each treated cell, followed by hybridizing on Human MicroRNA Expression profiling v2 panels (Illumina, San Diego, CA, USA) according to the manufacturer's instructions (Illumina MicroRNA Expression Profiling Assay Guide) and the method described previously (11). The Human v2 MicroRNA Expression Profiling kit contains 1,146 assays for detecting $>97 \%$ of the miRNAs described in the miRBase database, plus additional novel content derived using Illumina sequencing technology.

Array data processing and analysis were performed with Illumina BeadStudio software (www.illumina.com). The microRNA expression array was scanned and extracted using BeadScan, with the data corrected by background subtraction in the GenomeStudio module. The array intensity data were imported into BeadStudio v3.2 (Illumina), a software package that permits visualization and normalization of the data. The 'Average' normalization method was used for all analyses reported, with the exception of assay reproducibility, given the number of replicates. The normalized intensities and detection $\mathrm{P}$-values were exported and further analyzed using the $\mathrm{R}$ environment (version 2.6), in combination with Bio-conductor packages (12).

miRNAs were considered significantly differentially expressed if the P-values were $<0.05$ and the fold change ratio (FCR) was $>2$.

RT-qPCR of specific miRNAs. Validation of differential gene expression was performed for selected miRNAs, including miR181a, miR-148a, miR-99a, miR-195, miR-9, miR-335, miR-143, miR-145 and miR-539. These miRNAs were amplified using the Bulge-Loop ${ }^{\mathrm{TM}}$ miRNA qRT-PCR Primer Set (Ribobio, Guangzhou, China) (13). The thermal profile for the RT-qPCR was at $95^{\circ} \mathrm{C}$ for $1 \mathrm{~min}$, followed by 40 cycles of $95^{\circ} \mathrm{C}$ for $10 \mathrm{sec}$, $60^{\circ} \mathrm{C}$ for $20 \mathrm{sec}$ and $72^{\circ} \mathrm{C}$ for $5 \mathrm{sec}$ on a Bio-Rad CFX96 RT-qPCR system (Bio-Rad, Hercules, CA, USA). All qPCR reactions, including no-template controls, were performed in triplicate. Expression levels of each miRNA were evaluated using a comparative threshold cycle $(\mathrm{Ct})$ method normalized to that of U6. The fold changes of each miRNA were calculated from the expression levels in the MG-63 and HOB cell lines.

Bioinformatics analysis. The TarBase 6.0 database (http:// diana.cslab.ece.ntua.gr/) was used to investigate the validated target genes in cancer research (14). Moreover, following the collection of all the validated genes, the function of these genes was analyzed by previous literature and bioinformatics research. The chromosome location of these miRNAs and their target genes was investigated to exclude the potential bias of sex chromosomes and illustrate the complex and comprehensive mechanisms in miRNA regulation of the target gene expression.

\section{Results}

miRNA expression in the MG-63 and $\mathrm{HOB}$ cell lines. The fold changes (MG-63/HOB) were auto-analyzed by software (BeadStudio v3.2, Illumina). Of the 1,146 miRNAs detected in the microarray, 159 miRNAs were shown to be decreased and 109 miRNAs as increased. The various miRNAs were selected for further analysis as follows: i) the minimum value should be $>100$ in the two cell lines to eliminate the background value; ii) the fold changes should be $>5$ for improved accuracy. As Fig. 1 shows, 46 miRNAs were selected as differentially expressed between the MG-63 and HOB cell lines, of which 26 were underexpressed and 20 were overexpressed. The fold change was mainly $<10$, while several miRNAs in MG- 63 cells were markedly changed compared with the HOB cell line, including miR-335, miR-493, miR-494, miR-195 and miR-9.

Validation of miRNAs in the MG-63 and HOB cell lines. The RT-qPCR was employed to validate the differential expression of selected miRNAs. As Fig. 2 shows, it was revealed that 9 specific miRNAs were differentially expressed between the OS MG-63 and HOB cell lines and the differences are consistent with the microarray results shown. Therefore, it was demonstrated that these are the differentially expressed miRNAs in OS MG-63 compared with the HOB cell line.

\section{Bioinformatics research on these differential miRNAs and their target genes. Tables I and II show the target genes involved in the biological behavior of cancer and validated by previous literature. The functions of these target genes are complex as they are correlated with various cellular processes, including cell proliferation, differentiation, cell cycle, apop- tosis, signaling, migration and invasion. Moreover, miRNAs may regulate the expression and function of their target genes although they are located on various chromosomes.}

\section{Discussion}

The significance of miRNAs in the regulation of cellular processes has been increasingly noted (43). Up- and/or downregulation of miRNA expression in cancer suggests that miRNAs function as classical tumor suppressor genes or oncogenes (6-8). The expression fold changes of several miRNAs may aid in tumor stratification and clinical outcome prognosis $(44,45)$. Previous research shows that specific miRNA expression may be correlated with cancer recur- 
Table I. Validated target genes of the miRNAs in the increased group.

\begin{tabular}{|c|c|c|c|c|}
\hline miRNA & Location & Validated targets (ref.) & Location & Functions in cancer \\
\hline miR-195 & $17 \mathrm{p} 13.1$ & $\begin{array}{l}\text { CDK6 (15) } \\
\text { E2F3 (15) } \\
\text { CCND1 (15) } \\
\text { VEGFA (16) } \\
\text { Bcl-2 (17) } \\
\text { SKI (18) } \\
\text { BCL2L11 (18) } \\
\text { CDK4 (19) }\end{array}$ & $\begin{array}{l}7 \mathrm{q} 21-\mathrm{q} 22 \\
6 \mathrm{p} 22 \\
11 \mathrm{q} 13 \\
6 \mathrm{p} 12 \\
18 \mathrm{q} 21.3 \\
1 \mathrm{q} 22-\mathrm{q} 24 \\
2 \mathrm{q} 13 \\
12 \mathrm{q} 14\end{array}$ & $\begin{array}{l}\text { Cell cycle and arrest } \\
\text { Cell cycle and arrest } \\
\text { Cell cycle and arrest } \\
\text { Angiogenesis and metastasis regulation } \\
\text { Apoptosis regulation } \\
\text { Proto-oncogene } \\
\text { Apoptosis regulation } \\
\text { Cell cycle and arrest }\end{array}$ \\
\hline miR-99a & $21 \mathrm{q} 21.1$ & $\begin{array}{l}\text { MTOR (20) } \\
\text { FGFR3 (20) } \\
\text { SKI (21) } \\
\text { IGF1 (22) }\end{array}$ & $\begin{array}{l}1 \mathrm{p} 36.2 \\
4 \mathrm{p} 16.3 \\
1 \mathrm{q} 22-\mathrm{q} 24 \\
12 \mathrm{q} 23.2\end{array}$ & $\begin{array}{l}\text { Response to anti-cancer drugs } \\
\text { Mitogenesis and differentiation } \\
\text { Proto-oncogene } \\
\text { Anti-apoptosis }\end{array}$ \\
\hline $\operatorname{miR}-9$ & $1 q 22$ & $\begin{array}{l}\text { NF-KB1 (23) } \\
\text { CDH1 (24) } \\
\text { VEGFA (24) } \\
\text { VIM (24) } \\
\text { MMP13 (24) } \\
\text { BIK (25) }\end{array}$ & $\begin{array}{l}4 \mathrm{q} 24 \\
16 \mathrm{q} 22.1 \\
6 \mathrm{p} 12 \\
10 \mathrm{p} 13 \\
11 \mathrm{q} 22.3 \\
22 \mathrm{q} 13.31\end{array}$ & $\begin{array}{l}\text { Transcription regulation } \\
\text { Metastasis regulation } \\
\text { Angiogenesis and metastasis regulation } \\
\text { Cell attachment, migration and signaling } \\
\text { Invasion and metastasis regulation } \\
\text { Apoptosis regulation }\end{array}$ \\
\hline $\mathrm{miR}-148 \mathrm{a}$ & $7 \mathrm{p} 15.2$ & $\begin{array}{l}\text { CDC25B (26) } \\
\text { PTPN4 (21) } \\
\text { CDK19 (21) } \\
\text { ROCK1 (27) }\end{array}$ & $\begin{array}{l}20 \mathrm{p} 13 \\
2 \mathrm{q} 14.2 \\
6 \mathrm{q} 21 \\
18 \mathrm{q} 11.1\end{array}$ & $\begin{array}{l}\text { Cell cycle and arrest } \\
\text { Cell growth, differentiation, mitotic cycle } \\
\text { and oncogenic transformation } \\
\text { Cell cycle and arrest } \\
\text { Invasion and metastasis }\end{array}$ \\
\hline miR-181a & 1q32.1 & $\begin{array}{l}\text { CDKN1B (28) } \\
\text { Bcl-2 (29) } \\
\text { Hras (30) } \\
\text { CDX2 (31) } \\
\text { S100A1 (31) } \\
\text { KLF6 (32) }\end{array}$ & $\begin{array}{l}12 \mathrm{p} 13.1-\mathrm{p} 12 \\
18 \mathrm{q} 21.3 \\
11 \mathrm{p} 15.5 \\
13 \mathrm{q} 12.3 \\
1 \mathrm{q} 21 \\
10 \mathrm{p} 15\end{array}$ & $\begin{array}{l}\text { Cell cycle and arrest } \\
\text { Apoptosis regulation } \\
\text { Signal transduction } \\
\text { Cell growth and differentiation } \\
\text { Cell cycle and differentiation } \\
\text { Tumor suppressor }\end{array}$ \\
\hline
\end{tabular}

miR, miRNA, microRNA.
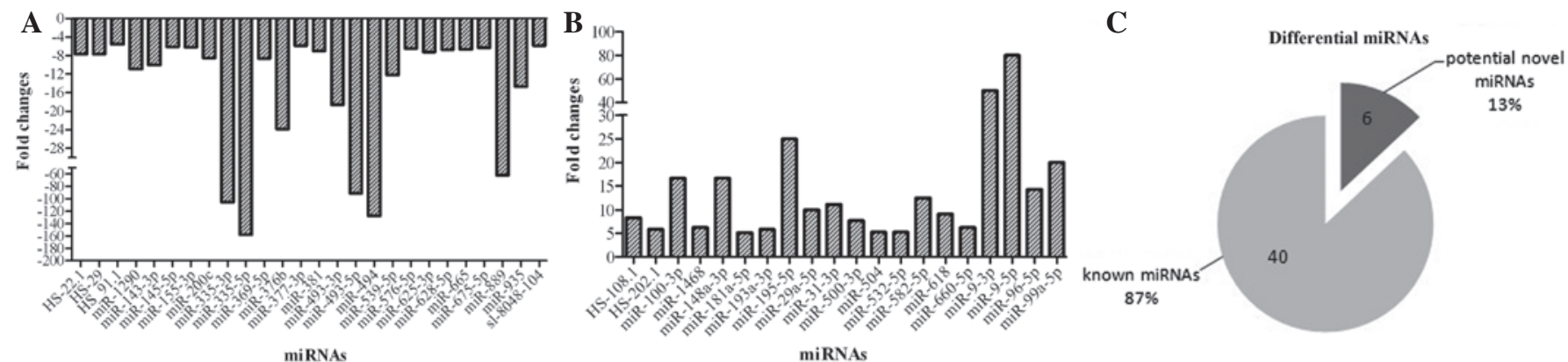

Figure 1. Alterations of miRNA expression in the OS MG-63 cell line compared with the osteoblast hFOB1.19 by microarray analysis. (A) There are 26 miRNAs in the decreased group. Negative values indicate downregulation in the MG-63 cell line compared with the hFOB1.19 cell line. (B) There are 20 miRNAs in the increased group. (C) These 46 miRNAs are identified as the differentially expressed miRNAs in OS compared with the osteoblast cell line. Of these, 40 miRNAs are known miRNAs in the miRBase, while the remaining 6 miRNAs are potentially novel miRNAs altered in OS. This suggests that there are new miRNAs involved in the carcinogenesis and development of OS. OS, osteosarcoma. miR, miRNA, microRNA.

rence. Therefore, the distinct difference between normal and abnormal cells may be correlated with the early diagnosis and treatment of the primary cancer or its recurrence.
Although there are several studies concerning specific miRNAs as the key biomarkers for the diagnosis, treatment and evaluation of the chemoresponse or chemoprevention in 
Table II. Validated target genes of the miRNAs in the decreased group.

\begin{tabular}{|c|c|c|c|c|}
\hline miRNA & Location & Validated targets (ref.) & Location & Functions in cancer \\
\hline miR-145 & $5 q 32$ & $\begin{array}{l}\text { FSCN1 }(33) \\
\text { MMP1 (34) } \\
\text { MMP12 (34) } \\
\text { MMP14 (34) } \\
\text { TP53 (35) }\end{array}$ & $\begin{array}{l}7 \mathrm{p} 22 \\
11 \mathrm{q} 22.3 \\
11 \mathrm{q} 22.3 \\
14 \mathrm{q} 11-\mathrm{q} 12 \\
17 \mathrm{p} 13.1\end{array}$ & $\begin{array}{l}\text { Cell migration, motility, adhesion and cellular interactions } \\
\text { Invasion and metastasis regulation } \\
\text { Invasion and metastasis regulation } \\
\text { Invasion and metastasis regulation } \\
\text { Proliferation and apoptosis regulation }\end{array}$ \\
\hline $\operatorname{miR}-143$ & $5 q 32$ & $\begin{array}{l}\text { MAPK7 (36) } \\
\text { MMP13 (37) } \\
\text { Bcl-2 (38) } \\
\text { Hras (39) } \\
\text { TP53 (35) }\end{array}$ & $\begin{array}{l}17 \mathrm{p} 11.2 \\
11 \mathrm{q} 22.3 \\
18 \mathrm{q} 21.3 \\
11 \mathrm{p} 15.5 \\
17 \mathrm{p} 13.1\end{array}$ & $\begin{array}{l}\text { Proliferation, differentiation, transcription regulation } \\
\text { Invasion and metastasis regulation } \\
\text { Apoptosis regulation } \\
\text { Signal transduction } \\
\text { Proliferation and apoptosis regulation }\end{array}$ \\
\hline miR-335 & $7 q 32.2$ & $\begin{array}{l}\text { SP1 (40) } \\
\text { IGF1R (40) } \\
\text { BRCA1 (40) } \\
\text { BIK (41) } \\
\text { SMAD3 (41) } \\
\text { SMAD9 (41) } \\
\text { PML (41) }\end{array}$ & $\begin{array}{l}12 \mathrm{q} 13.1 \\
15 \mathrm{q} 26.3 \\
17 \mathrm{q} 21 \\
22 \mathrm{q} 13.31 \\
15 \mathrm{q} 22.33 \\
2 \mathrm{q} 26 \\
15 \mathrm{q} 22\end{array}$ & $\begin{array}{l}\text { Cell proliferation, differentiation, apoptosis regulation } \\
\text { Anti-apoptosis } \\
\text { Tumor suppressor } \\
\text { Apoptosis regulation } \\
\text { Carcinogenesis } \\
\text { Carcinogenesis } \\
\text { Tumor suppressor }\end{array}$ \\
\hline miR-539 & $14 q 32.31$ & MITF (42) & 3p14.2-p14.1 & Cell proliferation \\
\hline
\end{tabular}

miR, miRNA, microRNA.
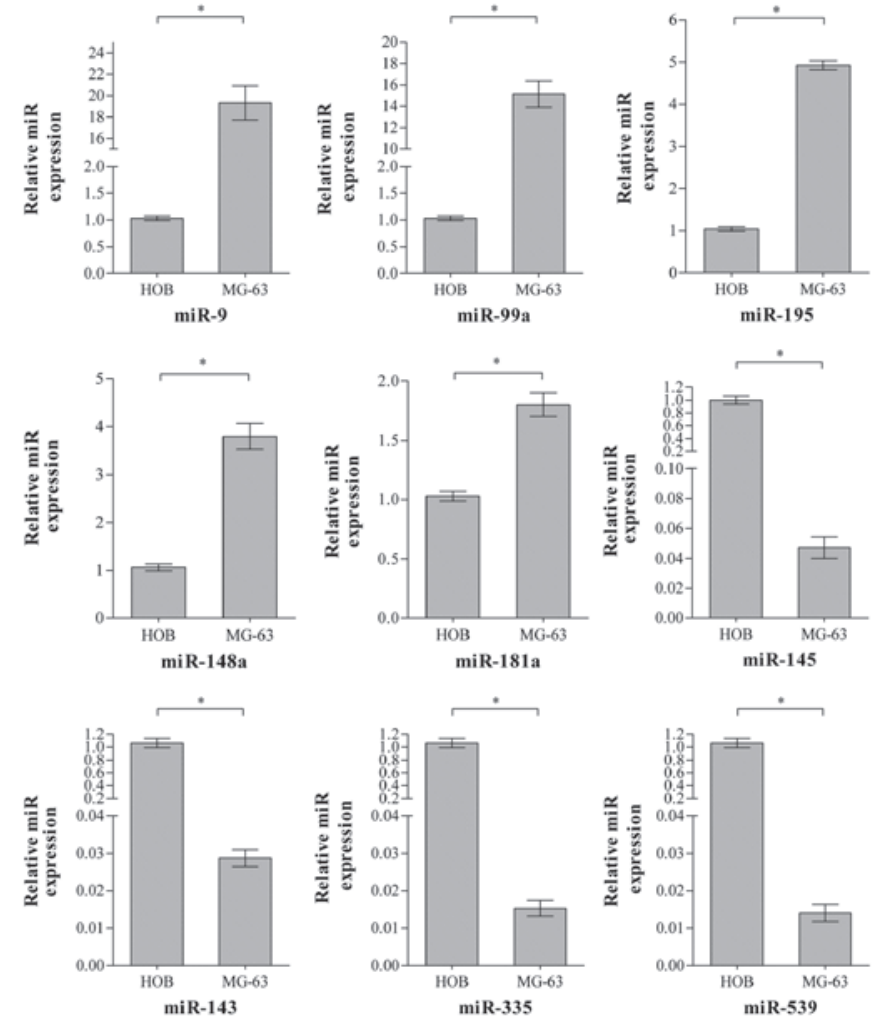

Figure 2. Validation of the selected miRNAs by real-time PCR. Differences of these 9 miRNAs between the OS and osteoblast cell lines are consistent with results of the microarray analysis. $2^{-\Delta \Delta} \mathrm{CT}$ is used to analyze the relative expression of miRNAs in MG-63 compared with hFOB 1.19 cells. The $\mathrm{CT}$ value is the fractional cycle number at which the fluorescence passes the fixed threshold. All data are expressed as mean \pm SEM of three independent experiments. ${ }^{*} \mathrm{P}<0.05$. OS, osteosarcoma; HOB, hFOB1.19 cell line; miR, miRNA, microRNA. cancer therapy $(46,47)$, little is known about miRNA profiling and its signature in OS. The explosion of microarray technology has led to its wide application in miRNA expression analysis. The miRNA microarray was employed to detect the miRNA profiling in the OS and HOB cell lines, respectively, and the real-time PCR was employed to validate the miRNA of interest or marked differences between these two cell lines. In the current study, 1,146 miRNAs were detected by the microarray, revealing 159 miRNAs as being part of the decreased group and 109 miRNAs as the increased group. Following further analysis of the miRNA microarray result, 46 miRNAs were selected as the differentially expressed miRNAs between the MG-63 and HOB cell lines.

Furthermore, based on previous research and the potential biological targets predicted by the various databases, including Targetscan and PicTar, 9 miRNAs were selected to validate their expression and demonstrate the difference between the two cell lines. The stem-loop RT-PCR method described in the present study is designed to detect and analyze mature miRNAs in a fast, specific, accurate and reliable manner (48). Therefore, RT-qPCR was employed to validate the expression of specific miRNAs of interest. Fig. 2 shows the expression of the selected 9 miRNAs quantified in the MG-63 and HOB cell lines. The differences of these miRNAs between the two cell lines are consistent with the microarray results shown. Therefore, these 9 miRNAs are accepted as the differentially expressed miRNAs between the MG-63 and HOB cell lines.

It is well known that the miRNAs involved in complex cancer-related cellular processes by regulating the various target mRNA expression and miRNAs are thought to be components of vast regulatory networks $(49,50)$. Previous research 
has confirmed that multiple miRNAs target the same gene, suggesting that the correlation between miRNAs and target genes are complex and interactive (51). Therefore, analysis of the target genes of these differential miRNAs may reveal their functions as oncogenes or anti-oncogenes. Furthermore, this analysis is likely to aid the fuller understanding of the biological function of specific miRNAs through analysis of their target genes and vice versa (52-54).

The validated target genes of these 9 miRNAs were obtained from bioinformatics research. Tables I and II show the validated target genes which have been demonstrated by previous research to be involved in various cellular process in cancer biology, including proliferation, differentiation, cell cycle, apoptosis, signaling, migration and invasion. These target genes are located on different chromosomes, suggesting that miRNAs may regulate the expression and function of mRNA although they are located on various chromosomes. These 9 miRNAs may play a significant role in the biological behavior of cancer, although they alter the target gene expression in different directions (7).

A total of 9 miRNAs have been reported that may act as biomarkers in the diagnosis, treatment and prediction of the prognosis of cancer. Previous evidence has demonstrated that miR-143 and miR-145, that belong to the same miRNA cluster, regulate the expression and function of various target genes. It is well known that the underexpression of the miR-143/145 cluster, the expression of which was decreased in OS in the current study, are strongly associated with carcinogenesis in various tumor types, suggesting that they may act as significant tumor suppressors (37). As Tables I and II demonstrate, tumor protein p53(TP53), fascin homolog 1(FSCN1), several matrix metallopeptidases (MMPs) and mitogen-activated protein kinases (MAPKs), which are regulated by the miR-143/145 cluster, may be involved in cancer cell proliferation, differentiation, gene transcription, apoptosis, migration and invasion (55). The similar effect of miR-143 and/or miR-145 has been demonstrated in OS cell lines by previous research (56). Therefore, we may conclude that the aberrant expression levels of the miR-143/145 clusters are correlated with the carcinogenesis and development of OS compared with the HOB cell line.

miR-9 is another of the widely-researched miRNAs in cancer biology (23-25). It has been shown that miR-9 is overexpressed in various tumor types, particularly in tumors with micro-metastasis. The validated target genes (NF-KB1, CDH1, VEGFA, VIM, MMP13 and BIK) shown in Table I suggest that miR-9 may act as a significant regulatory miRNA, which was also increased in OS in the current study compared with the HOB cell line.

A previous study demonstrated that 6 other miRNAs that were validated in the current study are also involved in the biology of cancer. Of these, miR-99a may play a significant role in cell growth and correlates with the prognosis of patients with specific tumors $(57,58)$. The aberrant expression of miR-195 in certain types of cancer may be an effective biomarker in diagnosis $(59,60)$. The differential expression of miR-148a has been reported to be a potential marker for colorectal cancer screening and prognosis (61). miR-181a, which has been recently demonstrated to be overexpressed miRNA in OS tissue, is correlated with cancer development, apoptosis evasion and cell proliferation (62). With regard to the reduced expression group, miR-335, which is also underexpressed in certain types of cancer, has also been demonstrated to be significant as a biomarker of metastatic tumor and maintain differentiation (63-65). Recently, it has been demonstrated that miR-539 may inhibit cell proliferation through suppressing the MITF expression (42). However, the functional study of the 6 miRNAs in the OS cell line are limited and ongoing research concerning their function may illustrate the further mechanism of these miRNAs in OS oncogenesis, development and metastasis.

In conclusion, the aberrant expression levels of specific miRNAs, including miR-9, miR-99a, miR-195, miR-148a, miR-181a, miR-143, miR-145, miR-335 and miR-539, may act as potential biomarkers in the diagnosis, treatment and prognosis prediction of OS. Further research on the function of their target genes may provide new insights into the biology and treatment of OS.

\section{Acknowledgements}

This study was supported by the Natural Science Foundation of China (No.30772185), the Fundamental Research Funds for the Central Universities (201130302020010).

\section{References}

1. Jemal A, Siegel R, Ward E, Murray T, Xu J and Thun MJ: Cancer statistics, 2007. CA Cancer J Clin 57: 43-66, 2007.

2. Messerschmitt PJ, Rettew AN, Brookover RE, Garcia RM, Getty PJ and Greenfield EM: Specific tyrosine kinase inhibitors regulate human osteosarcoma cells in vitro. Clin Orthop Relat Res 466: 2168-2175, 2008.

3. Bacci G, Longhi A, Versari M, Mercuri M, Briccoli A and Picci P: Prognostic factors for osteosarcoma of the extremity treated with neoadjuvant chemotherapy: 15 -year experience in 789 patients treated at a single institution. Cancer 106: 1154-1161, 2006.

4. Longhi A, Errani C, De Paolis M, Mercuri M and Bacci G: Primary bone osteosarcoma in the pediatric age: state of the art. Cancer Treat Rev 32: 423-436, 2006.

5. Zhang Y, Wei RX, Zhu XB, Cai L, Jin W and Hu H: Tanshinone IIA induces apoptosis and inhibits the proliferation, migration and invasion of the osteosarcoma MG-63 cell line in vitro. Anticancer Drugs 23: 212-219, 2012.

6. Kobayashi E, Hornicek FJ and Duan Z: MicroRNA involvement in osteosarcoma. Sarcoma 2012: 359739, 2012.

7. Lulla RR, Costa FF, Bischof JM, et al: Identification of differentially expressed microRNAs in osteosarcoma. Sarcoma 2011: $732690,2011$.

8. Lujambio A and Lowe SW: The microcosmos of cancer. Nature 482: 347-355, 2012.

9. Rottiers V and Näär AM: MicroRNAs in metabolism and metabolic disorders. Nat Rev Mol Cell Biol 13: 239-250, 2012.

10. Zhang W and Dolan ME: The emerging role of microRNAs in drug responses. Curr Opin Mol Ther 12: 695-702, 2010.

11. Wang L, Oberg AL, Asmann YW, et al: Genome-wide transcriptional profiling reveals microRNA-correlated genes and biological processes in human lymphoblastoid cell lines. PLoS One 11: e5878, 2009.

12. Zhao H, Shen J, Medico L, Wang D, Ambrosone CB and Liu S: A pilot study of circulating miRNAs as potential biomarkers of early stage breast cancer. PLoS One 5: e13735, 2010.

13. Guo L, Liu Y, Bai Y, Sun Y, Xiao F and Guo Y: Gene expression profiling of drug-resistant small cell lung cancer cells by combining microRNA and cDNA expression analysis. Eur $\mathbf{J}$ Cancer 46: 1692-1702, 2010.

14. Vergoulis T, Vlachos IS, Alexiou P, et al: TarBase 6.0: capturing the exponential growth of miRNA targets with experimental support. Nucleic Acids Res 40 (Database issue):D222-D229, 2012.

15. Xu T, Zhu Y, Xiong Y, Ge YY, Yun JP and Zhuang SM: MicroRNA-195 suppresses tumorigenicity and regulates G1/S transition of human hepatocellular carcinoma cells. Hepatology 50: 113-121, 2009. 
16. Ye W, Lv Q, Wong CK, et al: The effect of central loops in miRNA:MRE duplexes on the efficiency of miRNA-mediated gene regulation. PLoS One 3: e1719, 2008.

17. Liu L, Chen L, Xu Y, Li R and Du X: microRNA-195 promotes apoptosis and suppresses tumorigenicity of human colorectal cancer cells. Biochem Biophys Res Commun 400: 236-240, 2010

18. Murakami Y, Yasuda T, Saigo K, et al: Comprehensive analysis of microRNA expression patterns in hepatocellular carcinoma and non-tumorous tissues. Oncogene 25: 2537-2345, 2006.

19. Lin Y, Wu J, Chen H, et al: Cyclin-dependent kinase 4 is a novel target in micoRNA-195-mediated cell cycle arrest in bladder cancer cells. FEBS Lett 586: 442-447, 2012.

20. Oneyama C, Ikeda J, Okuzaki D, et al: MicroRNA-mediated downregulation of mTOR/FGFR3 controls tumor growth induced by Src-related oncogenic pathways Oncogene 30: 3489-3501, 2011

21. Hafner M, Landthaler M, Burger L, et al: Transcriptome-wide identification of RNA-binding protein and microRNA target sites by PAR-CLIP. Cell 141: 129-141, 2010.

22. Doghman M, El Wakil A, Cardinaud B, et al: Regulation of insulin-like growth factor-mammalian target of rapamycin signaling by microRNA in childhood adrenocortical tumors. Cancer Res 70: 4666-4675, 2010.

23. Guo LM, $\mathrm{Pu}$ Y, Han Z, et al: MicroRNA-9 inhibits ovarian cancer cell growth through regulation of NF-kappaB1. FEBS J 276: 5537-5546, 2009.

24. Ma L, Young J,Prabhala H, et al: miR-9, a MYC/MYCN-activated microRNA, regulates E-cadherin and cancer metastasis. Nat Cell Biol 12: 247-256, 2010.

25. Grimson A, Farh KK, Johnston WK, Garrett-Engele P, Lim LP and Bartel DP: MicroRNA targeting specificity in mammals: determinants beyond seed pairing. Mol Cell 27: 91-105, 2007.

26. Liffers ST, Munding JB, Vogt M, et al: MicroRNA-148a is down-regulated in human pancreatic ductal adenocarcinomas and regulates cell survival by targeting CDC25B. Lab Invest 91: 1472-1479, 2011

27. Zheng B, Liang L, Wang C, et al: MicroRNA-148a suppresses tumor cell invasion and metastasis by downregulating ROCK1 in gastric cancer. Clin Cancer Res 17: 7574-7583, 2011.

28. Cuesta R, Martínez-Sánchez A and Gebauer F: miR-181a regulates cap-dependent translation of p27(kip1) mRNA in myeloid cells. Mol Cell Biol 29: 2841-2851, 2009.

29. Zhu W, Shan X, Wang T, Shu Y and Liu P: miR-181b modulates multidrug resistance by targeting BCL2 in human cancer cell lines. Int J Cancer 127: 2520- 2529, 2010.

30. Shin KH, Bae SD, Hong HS, Kim RH, Kang MK and Park NH: miR-181a shows tumor suppressive effect against oral squamous cell carcinoma cells by downregulating K-ras. Biochem Biophys Res Commun 404: 896-902, 2011.

31. Ji J, Yamashita T, Budhu A, et al: Identification of microRNA-181 by genome- wide screening as a critical player in EpCAM-positive hepatic cancer stem cells. Hepatology 50: 472-480, 2009.

32. Zhang X, Nie Y, Du Y, Cao J, Shen B and Li Y: MicroRNA-181a promotes gastric cancer by negatively regulating tumor suppressor KLF6. Tumour Biol 33: 921-928, 2012.

33. Chiyomaru T, Enokida H, Tatarano S, et al: miR-145 and miR-133a function as tumour suppressors and directly regulate FSCN1 expression in bladder cancer. Br J Cancer 102: 883-891, 2010.

34. Kano M, Seki N, Kikkawa N, et al: miR-145, miR-133a and miR-133b: Tumor-suppressive miRNAs target FSCN1 in esophageal squamous cell carcinoma. Int J Cancer 127: 2804-2814, 2010.

35. Zhang J, Sun Q, Zhang Z, Ge S, Han ZG and Chen WT: Loss of microRNA- 143/145 disturbs cellular growth and apoptosis of human epithelial cancers by impairing the MDM2-p53 feedback loop. Oncogene 28: 1038-1046, 2012.

36. Akao Y, Nakagawa Y and Naoe T: MicroRNA-143 and -145 in colon cancer. DNA Cell Biol 26: 311-320, 2007.

37. Osaki M, Takeshita F, Sugimoto Y, et al: MicroRNA-143 regulates human osteosarcoma metastasis by regulating matrix metalloprotease-13 expression. Mol Ther 19: 1123-1130, 2011.

38. Borralho PM, Kren BT, Castro RE, da Silva IB, Steer CJ and Rodrigues CM: MicroRNA-143 reduces viability and increases sensitivity to 5-fluorouracil in HCT116 human colorectal cancer cells. FEBS J 276: 6689-6700, 2009.

39. Chen X, Guo X, Zhang H, et al: Role of miR-143 targeting KRAS in colorectal tumorigenesis. Oncogene 28: 1385-1392, 2009.

40. Heyn H, Engelmann M, Schreek S, et al: MicroRNA miR-335 is crucial for the BRCA1 regulatory cascade in breast cancer development. Int J Cancer 129: 2797- 2806, 2011.
41. Tavazoie SF, Alarcón C, Oskarsson T, et al: Endogenous human microRNAs that suppress breast cancer metastasis. Nature 451: 147-152, 2008.

42. Lee YN, Brandal S, Noel P, et al: KIT signaling regulates MITF expression through miRNAs in normal and malignant mast cell proliferation. Blood 117: 3629-3640, 2011.

43. Patnaik SK, Kannisto E and Yendamuri S: Overexpression of microRNA miR-30a or miR-191 in A549 lung cancer or BEAS-2B normal lung cell lines does not alter phenotype. PLoS One 5: e9219, 2010.

44. Kim J, Coffey DM, Creighton CJ, Yu Z, Hawkins SM and Matzuk MM: High-grade serous ovarian cancer arises from fallopian tube in a mouse model. Proc Natl Acad Sci USA 109: 3921-3926, 2012

45. Puerta-Gil P, García-Baquero R, Jia AY, et al: miR-143, miR-222 and miR-452 are useful as tumor stratification and noninvasive diagnostic biomarkers for bladder cancer. Am J Pathol 180: 1808-1815, 2012

46. Cortez MA, Welsh JW and Calin GA: Circulating microRNAs as noninvasive biomarkers in breast cancer. Recent Results Cancer Res 195: 151-161, 2012.

47. Mendell JT and Olson EN: MicroRNAs in stress signaling and human disease. Cell 148: 1172-1187, 2012.

48. Varkonyi-Gasic E and Hellens RP: Quantitative stem-loop RT-PCR for detection of microRNAs. Methods Mol Biol 744: 145-157, 2011.

49. Saito T and Saetrom P: MicroRNAs - targeting and target prediction. N Biotechnol 27: 243-249, 2010

50. Peter ME: Targeting of mRNAs by multiple miRNAs: the next step. Oncogene 29: 2161-2164, 2010.

51. Wu S, Huang S, Ding J, et al: Multiple microRNAs modulate p21Cip1/Waf1 expression by directly targeting its 3' untranslated region. Oncogene 29: 2302-2308, 2010.

52. Thomson DW, Bracken CP and Goodall GJ: Experimental strategies for microRNA target identification. Nucleic Acids Res 39: 6845-6853, 2011

53. Farazi TA, Spitzer JI, Morozov $\mathrm{P}$ and Tuschl T: miRNAs in human cancer. J Pathol 223: 102-115, 2011.

54. Shenouda SK and Alahari SK: MicroRNA function in cancer: oncogene or a tumor suppressor? Cancer Metastasis Rev 28: 369-378, 2009.

55. Zhang H, Cai X, Wang Y, Tang H, Tong D and Ji F: microRNA-143, down-regulated in osteosarcoma, promotes apoptosis and suppresses tumorigenicity by targeting Bcl-2. Oncol Rep 24: 1363-1369, 2010

56. Fan L, Wu Q, Xing X, Wei Y and Shao Z: MicroRNA-145 targets vascular endothelial growth factor and inhibits invasion and metastasis of osteosarcoma cells. Acta Biochim Biophys Sin (Shanghai) 44: 407-414, 2012

57. Li D, Liu X, Lin L, et al: MicroRNA-99a inhibits hepatocellular carcinoma growth and correlates with prognosis of patients with hepatocellular carcinoma. J Biol Chem 286: 36677-36685, 2011.

58. Sun D, Lee YS, Malhotra A, et al: miR-99 family of MicroRNAs suppresses the expression of prostate-specific antigen and prostate cancer cell proliferation. Cancer Res 71: 1313-1324, 2011.

59. Özata DM, Caramuta S, Velázquez-Fernández D, et al: The role of microRNA deregulation in the pathogenesis of adrenocortical carcinoma. Endocr Relat Cancer 18: 643-655, 2011.

60. Mahn R, Heukamp LC, Rogenhofer S, von Ruecker A, Müller SC and Ellinger J: Circulating microRNAs (miRNA) in serum of patients with prostate cancer. Urology 77: 1265.e9-16, 2011.

61. Cho WC: Epigenetic alteration of microRNAs in feces of colorectal cancer and its clinical significance. Expert Rev Mol Diagn 11: 691-694, 2011.

62. Jones KB, Salah Z, Del Mare S, et al: miRNA signatures associate with pathogenesis and progression of osteosarcoma. Cancer Res 72: 1865-1877, 2012.

63. White NM, Bao TT, Grigull J, et al: miRNA profiling for clear cell renal cell carcinoma: biomarker discovery and identification of potential controls and consequences of miRNA dysregulation. J Urol 186: 1077-1083, 2011.

64. Vickers MM, Bar J, Gorn-Hondermann I, et al: Stage-dependent differential expression of microRNAs in colorectal cancer: potential role as markers of metastatic disease. Clin Exp Metastasis 29: 123-132, 2012

65. Shu M, Zhou Y, Zhu W, et al: MicroRNA 335 is required for differentiation of malignant glioma cells induced by activation of cAMP/protein kinase A pathway. Mol Pharmacol 81: 292-298, 2012. 